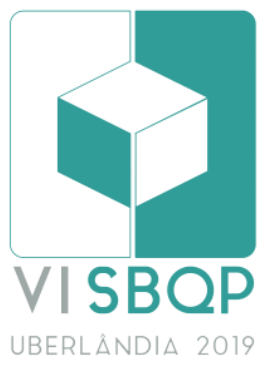

\title{
HABITAÇÃO MÍNIMA CONTEMPORÂNEA: ANÁLISE DE PARÂMETROS ERGONÔMICOS
}

\author{
KAPITZKY, Stephanie Heydy Avelino \\ Universidade Vila Velha, e-mail: stephaniekapitzky@gmail.com \\ MUNIZ, Andreia Fernandes \\ Universidade Vila Velha, e-mail: afernandesmuniz@gmail.com \\ CUNHA, Clóvis Aquino de Freitas \\ Universidade Vila Velha, e-mail: clovis.aquino@uvv.br
}

\begin{abstract}
RESUMO
Este artigo é a síntese de uma pesquisa de iniciação científica, que evoluiu para um trabalho final do curso de Arquitetura e Urbanismo e aborda a Habitação Mínima Contemporânea e seus padrões ergonômicos, que vem se tornando uma realidade cada vez mais presente no país, motivado pela alteração dos perfis familiares, o aumento do valor dos terrenos em áreas urbanas e a especulação imobiliária, que contribui para a redução da habitação, gerando ambientes cada vez menores que podem prejudicar o usuário na condição de conforto funcional e arranjo físico dos espaços. A pesquisa partiu da análise do dimensionamento dos ambientes em apartamentos com áreas reduzidas, construídos entre 2011 e 2016, período de maior crescimento na construção civil em Jardim Camburi/Vitória/ES, com enfoque nas dimensões mínimas estabelecidas pela legislação municipal e nos padrões ergonômicos mínimos de qualidade funcional dos ambientes. A partir da análise das plantas das unidades foi possível obter um diagnóstico sobre os aspectos dimensionais praticados, comparando-os à legislação vigente e a parâmetros ergonômicos que qualificam os espaços. Como resultados foram propostas modificações na planta baixa com área útil média, definida de acordo com as plantas catalogadas durante a pesquisa. As alterações foram baseadas em parâmetros ergonômicos e de desempenho, que contribuem para a qualidade de projeto.
\end{abstract}

Palavras-chave: Habitação, Ergonomia do Ambiente Construído, Dimensionamento Habitacional, Ambientes Mínimos.

\begin{abstract}
This article is the synthesis of a scientific initiation research, which evolved to a final work of the Architecture and Urbanism course and approaches the Minimum Contemporary Housing and its ergonomic standards, which is becoming an increasingly present reality in the country, motivated by the alteration of family profiles, increasing the value of land in urban areas and real estate speculation, which contributes to the reduction of housing, generating smaller and smaller environments that can harm the user in the condition of functional comfort and physical arrangement of spaces. The research was based on the analysis of the sizing of the rooms in apartments with reduced areas, constructed between 2011 and 2016, the period of greatest growth in civil construction in Jardim Camburi / Vitória / ES, focusing on the minimum dimensions established by municipal legislation and minimum ergonomic standards of functional quality of the environments. From the analysis of the plants of the units it was possible to obtain a diagnosis on the dimensional aspects practiced, comparing them to the current legislation and the ergonomic parameters that qualify the spaces. As results, modifications were proposed in the low plant with average useful area, defined according to the plants cataloged during the research. The changes were based on ergonomic and performance parameters, which contribute to the design quality.
\end{abstract}

Keywords: Housing, Built Environment Ergonomics, Housing Dimensioning, Minimum Environments.

KAPITZKY, S. H. A; MUNIZ, A. F.; CUNHA, C. A. F. Habitação Mínima Contemporânea: Análise de Parâmetros Ergonômicos. In: SIMPÓSIO BRASILEIRO DE QUALIDADE DO PROJETO NO AMBIENTE CONSTRUÍDO, 6., 2019, Uberlândia. Anais... Uberlândia: PPGAU/FAUeD/UFU, 2019. p. 320-332. DOI https://doi.org/10.14393/sbqp19031. 


\section{INTRODUÇÃO}

O conceito de habitação mínima surgiu por volta do século XX, após a Primeira Guerra Mundial, com o intuito de solucionar os problemas econômicos e sociais gerados por conta deste conflito ocorrido na Europa (CASELLI, 2007).

Em 1929, o Congresso Internacional de Arquitetura (CIAM), iniciou o debate sobre um novo cenário habitacional de uso coletivo, influenciado por fatores como superpopulação, déficit habitacional, edificações inseguras e insalubridade ligando aos aspectos econômicos e construtivos, motivando a racionalização das edificações, que seriam planejadas para o mínimo existencial, considerando não somente a metragem da construção como também as necessidades psicológicas e biológicas dos usuários nos projetos.

A habitação mínima possuía a ideia de proporcionar qualidade e conforto para o usuário, para que pudesse suprir as suas necessidades básicas sob um menor custo imaginável. Porém, não havia uma definição concreta para o mínimo necessário, sendo algo alusivo quando comparado a renda, localização e ao usuário (CASELLI, 2007).

Porém, um fator que acabou dominando o novo modelo habitacional foi o controle dos valores das edificações por meio da especulação imobiliária, fazendo com que o conceito do ambiente mínimo fosse construído por meio do menor custo possivel, sem se preocupar com a qualidade da habitação e em atender as necessidades psicológicas e físicas do usuário, se contrapondo aos ideais dos arquitetos modernistas (CASELLI, 2007).

No mercado imobiliário vemos a crescente oferta de unidades habitacionais com áreas reduzidas, projetadas com espaços mínimos, que não comportam todas as necessidades dos futuros moradores, consequência da redução da oferta de terrenos em áreas urbanas consideradas valorizadas, dos novos arranjos familiares, do aumento do valor do $\mathrm{m}^{2}$ dos imóveis e até mesmo da especulação imobiliária.

A redução significativa das dimensões de um espaço de habitação pode prejudicar o usuário, tanto nos aspectos de conforto funcional quanto no arranjo físico dos ambientes. Estes aspectos têm sido mais relevantes nos últimos anos, principalmente na tipologia de habitação denominada "apartamento", com empreendimentos sendo comercializados com áreas cada vez mais reduzidas.

Tal prática, apoiada pela legislação vigente, que tolera áreas mínimas para ambientes que em muitos casos, desconsideram princípios ergonômicos é vista em projetos desenvolvidos por profissionais habilitados, arquitetos e engenheiros, que necessitam desenvolver uma conscientização sobre os prejuízos causados aos futuros usuários destas moradias. Ambientes mínimos são aqueles que possuem os menores índices dimensionais permitidos pelas normas municipais para aprovação do projeto arquitetônico.

Nesta abordagem problemática, esta pesquisa se propôs a analisar 0 dimensionamento dos apartamentos com áreas reduzidas, tendo como base as plantas dos empreendimentos produzidos nos últimos 5 anos no bairro Jardim Camburi, localizado em Vitória/ES, local que mostrou um significativo crescimento habitacional na última década e com grande número de lançamentos de novos empreendimentos. 
Além disso, foram propostas modificações nas plantas de um apartamentotipo catalogado durante a pesquisa. As alterações foram baseadas em parâmetros ergonômicos, que contribuem para a qualidade de projeto.

\section{FUNDAMENTAÇÃO TEÓRICA}

Baseada na importância do conhecimento do corpo humano, a Ergonomia fundamenta o processo de decisão desde a concepção do projeto, principalmente quanto às questões dimensionais, sendo responsável pela melhoria da qualidade da moradia. Ela é caracterizada pelo uso das condições físicas e psicológicas humanas adaptadas ao ambiente, para isso, é necessário que o projeto seja elaborado buscando um funcionamento harmonioso com o usuário, por meio do dimensionamento de áreas compatíveis com as capacidades e limitações do indivíduo, não havendo desconforto, inconveniências ou ferimentos por parte deste (COSTA FILHO, 2005).

Como ciência, a Ergonomia aplicado ao ambiente construído trata de aspectos relacionados ao dimensionamento dos espaços, à adequação dos ambientes à realização das tarefas e à avaliação funcional e comportamental dos espaços, objetivando a satisfação e o bem-estar do usuário. Para que isso aconteça, deve-se compreender que o dimensionamento do espaço decorre das atividades necessárias ao funcionamento da edificação.

O espaço de atividades é a superfície necessária e suficiente para que uma pessoa possa desenvolver qualquer atividade sem interferência ou restrição ocasionada por mobiliário, equipamento e/ou componentes da edificação (BOUERI, 2008).

Conforme a figura 1, baseada nas recomendações de Boveri (2008), temos a representação do espaço de atividades para cada setor de uma habitação formada por: sala de estar e jantar, área de repouso, banheiro, cozinha e área de serviço. Desse modo, temos a área indicada para a execução de determinada atividade nos ambientes domésticos. No desenho são apontados um nível mínimo de espaço ergonômico com competência, com a medida dos mobiliários e equipamentos fornecidos pelos sites das lojas (BOUERI, 2008).

Verifica-se a importância da ergonomia aplicada ao edifício, principalmente à tipologia de habitação denominada habitação multifamiliar, que surge no Brasil sob a terminologia habitação coletiva, na metade do século XIX, na forma de estalagens e cortiços e, posteriormente, evolviu para o padrão moderno e contemporâneo do edifício de apartamento (VAZ, 2002), caracterizando um novo modo de morar nos anos 20 , onde famílias habitam edifícios verticais, distribuídas em unidades autônomas e compartilhando espaços comuns.

Ao longo dos anos, o espaço de morar evoluiu e sofreu diferentes alterações, tendo em vista as transformações da família, caracterizada por diferentes perfis com necessidade de espaços diferentes para o desenvolvimento das atividades na moradia. Além disso, o adensamento das cidades, que elevou o valor dos terrenos e a especulação imobiliária, levaram à diminuição dos espaços de morar, com a oferta cada vez maior de apartamentos com áreas reduzidas (MENDONÇA; VILLA, 2016). 
SETOR DE SERVIÇO

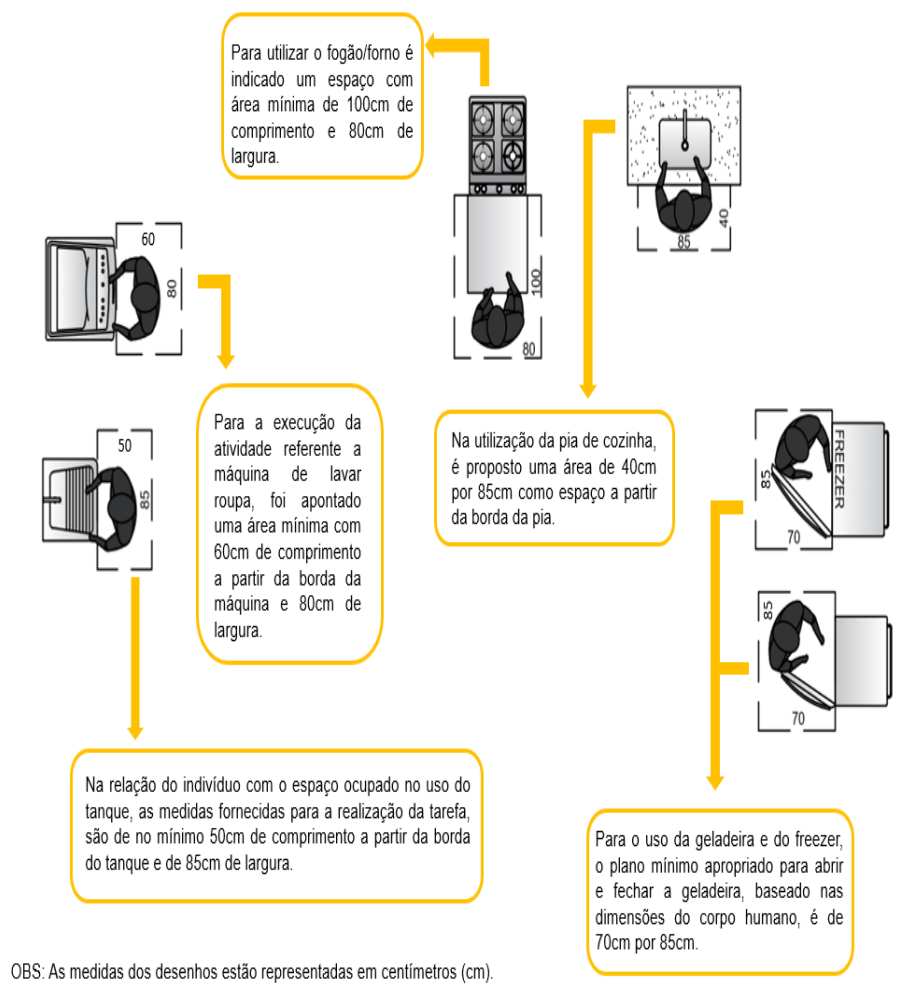

SETOR DE SOCIAL/PRIVADO

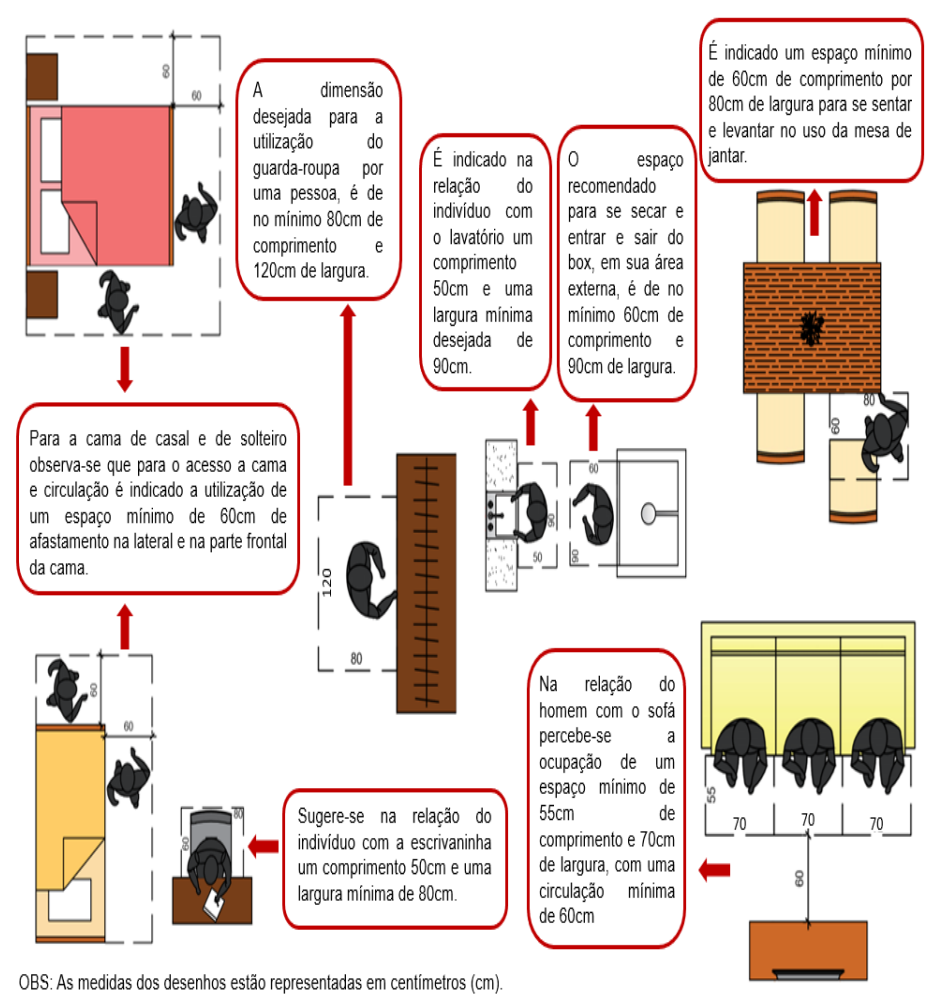

Figura 1 - Área proposta para execução de atividades na habitação Fonte: Adaptado de Boueri (2008) pelos autores, 2018.

Apartamentos com ambientes com áreas mínimas são aqueles que possuem os menores índices dimensionais tolerados pela legislação municipal para a aprovação, o Código de Obras. Tais tipologias de apartamentos tornaram-se muito comuns em áreas urbanas da Grande Vitória, principalmente em áreas de expansão imobiliária. 
Esse é um fator que demonstra que as diretrizes ergonômicas nem sempre recebem a devida atenção na hora de elaborar a legislação para cada região, além do fato de possuírem um longo prazo para a sua atualização, tornando-se inapropriadas para o contexto atual da sociedade e com isso gerando diversos conflitos. Com base nesse questionamento, foram elaboradas tabelas baseadas na Norma de Desempenho de Edificações Habitacionais (ABNT NBR 15.575: 2013) relacionando ao espaço de atividades indicado por Boveri (2008).

A tabela 1, foi elaborada conforme a NBR 15.575:2013, que se baseia na relação entre os mobiliários e os equipamentos que compõem os cômodos das residências, facilitando na escolha do essencial para o uso dos ambientes na fase de concepção do projeto. São apresentados os setores: social (sala de estar/jantar e cômodo para estudo/entretenimento), serviço (área de serviço) e privado (dormitórios e banheiro).

Ao observar a tabela 1, que indica a área recomendável para cada ambiente em função do mobiliário e das atividades desempenhadas, verificase que por meio do conjunto dessas funções pode-se obter uma área útil mínima, em uma habitação de dois quartos, de $30,27 \mathrm{~m}^{2}$ sendo que ainda não foram considerados os espaços para circulação e nem um layout definitivo, tendo em vista que essa medida irá sofrer um aumento significativo por conta desses fatores.

Tabela 1 - Relação do mobiliário da norma de desempenho (NBR 15.575:2013) com o espaço de atividades.

\begin{tabular}{|c|c|c|c|c|c|c|c|}
\hline \multirow{3}{*}{ Ambiente } & \multicolumn{3}{|c|}{ Mobiliário (NBR 15.575) } & \multicolumn{3}{|c|}{$\begin{array}{l}\text { Espaço para atividades (BOUERI, } \\
\text { 2008) }\end{array}$} & \multirow{3}{*}{$\begin{array}{c}\text { Área } \\
\text { estipulada } \\
\text { para o } \\
\text { ambiente, } \\
\text { baseada em } \\
\text { uma } \\
\text { quantidade de } \\
\text { usuário que o } \\
\text { mobiliário } \\
\text { permite }\left(\mathrm{m}^{2}\right)\end{array}$} \\
\hline & \multirow[t]{2}{*}{$\begin{array}{l}\text { Móvel ou } \\
\text { equipamento }\end{array}$} & \multicolumn{2}{|c|}{$\begin{array}{l}\text { Dimensões } \\
(\mathrm{m})\end{array}$} & \multirow[t]{2}{*}{ Atividade } & \multicolumn{2}{|c|}{$\begin{array}{c}\text { Dimensões } \\
\text { do espaço } \\
\text { ocupado } \\
\text { por uma } \\
\text { pessoa } \\
\left(\mathrm{m}^{2}\right)\end{array}$} & \\
\hline & & $\mathbf{L}$ & $\mathbf{P}$ & & $\mathbf{L}$ & $\mathbf{P}$ & \\
\hline \multirow{3}{*}{$\begin{array}{l}\text { Sala de } \\
\text { estar/jantar }\end{array}$} & $\begin{array}{l}\text { Sofá de } 3 \text { lugares } \\
\text { com braço }\end{array}$ & 1,70 & 0,70 & \multicolumn{3}{|c|}{\begin{tabular}{|l|l|l|} 
Sentar e levantar & 0,90 & 0,55 \\
É indicado a distância de $1,00 \mathrm{~m}$ \\
entre a TV e o indivíduo sentado, \\
de acordo com uma TV de $21 "$
\end{tabular}} & \multirow{3}{*}{7,65} \\
\hline & $\begin{array}{l}\text { Estante/armário } \\
\text { para TV }\end{array}$ & 0,80 & 0,50 & \multicolumn{3}{|c|}{\begin{tabular}{|l|} 
É indicado a distância de $1,00 \mathrm{~m}$ \\
entre a TV e o indivíduo sentado, \\
de acordo com uma TV de $21 "$
\end{tabular}} & \\
\hline & $\begin{array}{l}\text { Mesa retangular } \\
\text { para } 4 \text { lugares }\end{array}$ & 1,20 & 0,80 & $\begin{array}{l}\text { Sentar e levantar (4 } \\
\text { pessoas) }\end{array}$ & 0,80 & 0,60 & \\
\hline \multirow{4}{*}{ Cozinha } & Pia & 1,20 & 0,50 & Lavar a louça & 0,85 & 0,40 & \multirow{4}{*}{3,55} \\
\hline & Fogão & 0,55 & 0,60 & $\begin{array}{l}\text { Abertura da tampa } \\
\text { do forno para seu } \\
\text { uso }\end{array}$ & 0,80 & 1,00 & \\
\hline & Geladeira & 0,70 & 0,70 & Abrir a geladeira & 0,85 & 0,70 & \\
\hline & $\begin{array}{l}\text { Armário sob a } \\
\text { pia }\end{array}$ & - & - & - & - & - & \\
\hline Circulação & \multicolumn{7}{|c|}{ Varia de acordo com a forma e composição do ambiente } \\
\hline Varanda & \multicolumn{7}{|l|}{ Área variável } \\
\hline $\begin{array}{l}\text { Dormitório } \\
\text { casal }\end{array}$ & Cama de casal & 1,40 & 1,90 & $\begin{array}{l}\text { Circulação, fazer a } \\
\text { cama e ajudar } \\
\text { pessoa deitada }\end{array}$ & $\begin{array}{l}0,60 \\
\text { espac } \\
\text { em } \\
\text { da cc }\end{array}$ & $\begin{array}{l}\text { m de } \\
\text { ço } \\
\text { volta } \\
\text { ama }\end{array}$ & 8,45 \\
\hline
\end{tabular}




\begin{tabular}{|c|c|c|c|c|c|c|c|}
\hline \multirow{3}{*}{ Ambiente } & \multicolumn{3}{|c|}{ Mobiliário (NBR 15.575) } & \multicolumn{3}{|c|}{$\begin{array}{l}\text { Espaço para atividades (BOUERI, } \\
\text { 2008) }\end{array}$} & \multirow{3}{*}{$\begin{array}{c}\text { Área } \\
\text { estipulada } \\
\text { para o } \\
\text { ambiente, } \\
\text { baseada em } \\
\text { uma } \\
\text { quantidade de } \\
\text { usuário que o } \\
\text { mobiliário } \\
\text { permite }\left(\mathrm{m}^{2}\right)\end{array}$} \\
\hline & \multirow[t]{2}{*}{$\begin{array}{l}\text { Móvel ou } \\
\text { equipamento }\end{array}$} & \multicolumn{2}{|c|}{$\begin{array}{l}\text { Dimensões } \\
\text { (m) }\end{array}$} & \multirow[t]{2}{*}{ Atividade } & \multicolumn{2}{|c|}{$\begin{array}{c}\text { Dimensões } \\
\text { do espaço } \\
\text { ocupado } \\
\text { por uma } \\
\text { pessoa } \\
\left(\mathrm{m}^{2}\right)\end{array}$} & \\
\hline & & $\mathbf{L}$ & $\mathbf{P}$ & & $\mathbf{L}$ & $\mathbf{P}$ & \\
\hline & 2 Criados-mudos & 0,50 & 0,50 & $\begin{array}{l}\text { Utilizar utensílio na } \\
\text { cabeceira }\end{array}$ & 0,60 & 0,50 & \\
\hline & Guarda roupa & 1,50 & 0,50 & $\begin{array}{l}\text { Espaço para usar o } \\
\text { guarda roupa }\end{array}$ & 1,20 & 0,80 & \\
\hline \multirow{3}{*}{\begin{tabular}{l|} 
Dormitório \\
para \\
pessoa
\end{tabular}} & $\begin{array}{l}\text { Cama de } \\
\text { solteiro }\end{array}$ & 0,80 & 1,90 & $\begin{array}{l}\text { Circulação e fazer a } \\
\text { cama }\end{array}$ & \multicolumn{2}{|c|}{$\begin{array}{l}0,60 \mathrm{~m} \text { em } \\
\text { volta da } \\
\text { cama }\end{array}$} & \multirow{3}{*}{6,02} \\
\hline & Armário & 1,20 & 0,50 & $\begin{array}{l}\text { Espaço para usar o } \\
\text { guarda roupa }\end{array}$ & 1,20 & 0,80 & \\
\hline & Mesa de estudo & 0,80 & 0,60 & sentar e levantar & 0,80 & 0,60 & \\
\hline \multirow{3}{*}{ Banheiro } & Lavatório & 0,39 & 0,29 & $\begin{array}{l}\text { Lavar as mãos/rosto } \\
\text { e escovar os dentes }\end{array}$ & 0,90 & 0,50 & \multirow[b]{3}{*}{2,39} \\
\hline & $\begin{array}{l}\text { Vaso sanitário } \\
\text { (caixa } \\
\text { acoplada) }\end{array}$ & 0,60 & 0,70 & - & - & - & \\
\hline & Box quadrado & 0,80 & 0,80 & $\begin{array}{l}\text { Para entrar/ sair do } \\
\text { box e se secar (área } \\
\text { externa ao box) }\end{array}$ & 0,90 & 0,60 & \\
\hline \multirow{2}{*}{$\begin{array}{l}\text { Área de } \\
\text { serviço }\end{array}$} & Tanque & 0,52 & 0,53 & Lavar roupa & 0,85 & 0,60 & \multirow[b]{2}{*}{2,21} \\
\hline & $\begin{array}{l}\text { Máq. De lavar } \\
\text { roupa }\end{array}$ & 0,60 & 0,65 & $\begin{array}{l}\text { Acesso para a } \\
\text { máquina de lavar }\end{array}$ & 1,00 & 0,60 & \\
\hline $\begin{array}{l}\text { Área total } \\
\qquad\left(\mathrm{m}^{2}\right)\end{array}$ & \multicolumn{7}{|c|}{30,27} \\
\hline
\end{tabular}

Fonte: Elaborada pelos autores, com base nas referências da norma NBR 15.575:2013 e Boveri (2008).

As tabelas 2 e 3 comparam dois Códigos de Obras, Norma de Desempenho de Edificações Habitacionais (ABNT NBR 15575, 2013), diretrizes ergonômicas estipuladas por Boveri (2008) e as dimensões de área média útil encontradas durante a pesquisa de Iniciação Científica, que teve como base plantas baixas de apartamentos catalogadas durante a pesquisa.

Tabela 2 - Comparação entre parâmetros dimensionais estabelecidos em diferentes referências.

\begin{tabular}{|c|c|c|c|}
\hline $\begin{array}{c}\text { Ambientes } \\
\mathrm{m}^{2}\end{array}$ & $\begin{array}{c}\text { Tipologia } \\
\text { apartamento } 2 \\
\text { quartos com suíte. } \\
\text { De acordo com } \\
\text { pesquisa de MUNIZ; } \\
\text { LOUREIRO; KAPITZKY } \\
(2017)\end{array}$ & $\begin{array}{l}\text { Tipologia } 2 \text { quartos } \\
\text { De acordo com } \\
\text { Boueri (2008) }\end{array}$ & $\begin{array}{l}\text { Código de Obras Municipal de } \\
\text { Vitória/ES } \\
\text { Para tipologia unifamiliar/multifamiliar }\end{array}$ \\
\hline $\begin{array}{l}\text { Sala de } \\
\text { estar }\end{array}$ & 13,94 & 15 & $\begin{array}{l}7,5 \mathrm{~m}^{2} \text { de área mínima e possibilitar a } \\
\text { inscrição de um círculo no plano do } \\
\text { piso com diâmetro de } 2,00 \mathrm{~m}\end{array}$ \\
\hline
\end{tabular}




\begin{tabular}{|c|c|c|c|}
\hline $\begin{array}{l}\text { Ambientes } \\
\mathrm{m}^{2}\end{array}$ & $\begin{array}{c}\text { Tipologia } \\
\text { apartamento } 2 \\
\text { quartos com suíte. } \\
\text { De acordo com } \\
\text { pesquisa de MUNIZ; } \\
\text { LOUREIRO; KAPITZKY } \\
(2017)\end{array}$ & $\begin{array}{l}\text { Tipologia } 2 \text { quartos } \\
\text { De acordo com } \\
\text { Boueri (2008) }\end{array}$ & $\begin{array}{l}\text { Código de Obras Municipal de } \\
\text { Vitória/ES } \\
\text { Para tipologia unifamiliar/multifamiliar }\end{array}$ \\
\hline Varanda & 6,09 & & $\begin{array}{l}\text { Possibilitar a inscrição de um círculo no } \\
\text { plano do piso com diâmetro de } 0,80 \mathrm{~m} \text {. }\end{array}$ \\
\hline $\begin{array}{l}\text { Área de } \\
\text { serviço }\end{array}$ & 2,48 & 5,4 & $\begin{array}{c}\text { Possibilitar a inscrição de um círculo no } \\
\text { plano do piso com diâmetro de a, } \\
1,30 \mathrm{~m}\end{array}$ \\
\hline Cozinha & 6,03 & 7,2 & $\begin{array}{c}\text { Possibilitar a inscrição de um círculo no } \\
\text { plano do piso com diâmetro de a, } \\
1,50 \mathrm{~m}\end{array}$ \\
\hline Quarto & 7,9 & 12 & \multirow{2}{*}{$\begin{array}{c}\text { 7,5 } \mathrm{m}^{2} \text { de área e possibilitar a inscrição } \\
\text { de um círculo no plano do piso com } \\
\text { diâmetro de } 2,00 \mathrm{~m} \text {. Sendo que } \\
\text { quando há mais de dois } \\
\text { compartimentos destinados a repouso, } \\
\text { nas unidades habitacionais, um deles } \\
\text { poderá ter área mínima de } 4,00 \mathrm{~m}^{2} \text {. }\end{array}$} \\
\hline $\begin{array}{l}\text { Quarto } \\
\text { casal }\end{array}$ & 10,62 & 14 & \\
\hline $\begin{array}{l}\text { Banheiro } \\
\text { suíte }\end{array}$ & 2,88 & & \multirow{2}{*}{ Deve conter área mínima de $2,00 m^{2}$. } \\
\hline $\begin{array}{l}\text { Banheiro } \\
\text { social }\end{array}$ & 2,81 & 4,2 & \\
\hline $\begin{array}{l}\text { Área total } \\
\qquad\left(\mathrm{m}^{2}\right)\end{array}$ & 52,75 & 57,80 & Não estabelece área mínima \\
\hline
\end{tabular}

\section{Tabela 3 - Comparação entre parâmetros dimensionais estabelecidos em diferentes referências.}

\footnotetext{
1 - Código de Obras Municipal de São Paulo/SP para tipologia unifamiliar/multifamiliar.

De acordo com o novo Código de Obras de São Paulo/SP, Lei no 16.642, de 9 (nove) de maio de 2017, não são estabelecidas características relacionadas ao dimensionamento dos ambientes e nem ao programa de uma habitação, sendo que é exigido apenas para o banheiro, em unidade residencial, no mínimo 1 (uma) bacia, 1 (um) lavatório e 1 (um) chuveiro. Dessa forma, é deixado aos projetistas a competência de formatar os ambientes da habitação evitando conflitos com legislações estaduais ou municipais que versam sobre dimensões mínimas dos ambientes.

Portanto, não estabelece área mínima.
}

\section{2 - PROGRAMA MINHA CASA MINHA VIDA (renda de 0 a três salários mínimos) para tipologia Casa e Apartamentos (2 quartos).}

De acordo com o Programa as dimensões dos compartimentos: compatível com mobiliário mínimo. Especificações não estabelecem área mínima de cômodos, deixando aos projetistas a competência de formatar os ambientes da habitação segundo o mobiliário previsto, evitando conflitos com legislações estaduais ou municipais que versam sobre dimensões mínimas dos ambientes.

Tipologia Casa: sala, cozinha, banheiro, 2 dormitórios, área externa com tanque. A área mínima de casa deve ser a resultante das dimensões mínimas atendendo o mobiliário mínimo definido nestas especificações mínimas, considerando-se dois dormitórios, sala de estar/refeições, cozinha, banheiro e circulação, não podendo ser inferior à $36,00 \mathrm{~m}^{2}$, se área de 
serviço externa, ou $38,00 \mathrm{~m}^{2}$, se a área de serviços for interna.

A unidade habitacional deverá ser projetada de forma a possibilitar a sua futura ampliação sem prejuízo das condições de iluminação e ventilação natural dos cômodos pré-existentes. Área mínima da tipologia apartamento deve ser a resultante das dimensões mínimas atendendo o mobiliário mínimo definido no item 1 destas especificações mínimas, considerando-se dois dormitórios, sala de estar/refeições, cozinha, banheiro, área de serviço e circulação, não podendo ser inferior à $39,00 \mathrm{~m}^{2}$.

Portanto, estabelece área máxima para atender ao perfil socioeconômico.

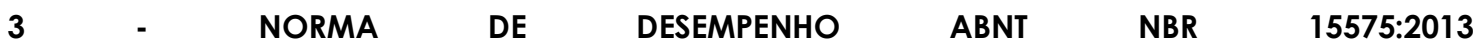 Item 7.2. pág.126 Manual CIBIC: DISPONIBILIDADE MÍNIMA DE ESPAÇOS PARA USO E OPERAÇÃO DA HABITAÇĀO}

A norma indica as atividades designadas para determinados cômodos e o mínimo de mobiliários necessário para execução de tais atividades, mas não estabelece dimensões mínimas dos ambientes, deixando aos projetistas a competência de formata-los dentro da habitação segundo o mobiliário previsto, evitando conflitos com legislações estaduais ou municipais que versam sobre dimensões mínimas dos ambientes. Os ambientes da habitação devem apresentar espaços compatíveis com as necessidades humanas (cozinhar, estudar, repousar, etc), recomendando-se que sejam projetados para acomodar os móveis e equipamentos-padrão relacionados nas tabelas apresentadas nas pág. 67 e 68 da parte 1 da norma.

Fonte: Elaborada pelos autores, 2018.

Percebe-se que as normas e as legislações determinam ambientes ou áreas estipuladas para esses ambientes, outras deixas as decisões a critério do projetista.

As referências dimensionais pesquisadas, em conjunto com os parâmetros ergonômicos auxiliaram nas propostas para redimensionamento das plantas dos apartamentos utilizados na pesquisa.

\section{METODOLOGIA}

Maior bairro da capital Vitória, com 39.157mil moradores, o bairro Jardim Camburi é um exemplo de expansão imobiliária (PREFEITURA DE VITÓRIA, 2016), resultado da proximidade com duas grandes empresas, a ArcelorMittal Tubarão e a Vale, a presença de grande oferta de serviços e comércio e a boa infraestrutura local. Surgido em 1967 de um loteamento com 100 casas, o bairro é considerado um dos mais promissores pelo mercado imobiliário, com uma margem de crescimento de 15\% ao ano (CRECI-ES, 2016), uma elevada valorização de imóveis e número de lançamentos (GAZETAONLINE, 2013).

Neste contexto, Jardim Camburi foi escolhido para a pesquisa, que realizou um levantamento dos apartamentos com áreas de até $70 \mathrm{~m}^{2}$, a partir das plantas baixas disponibilizadas em peças publicitárias pelas construtoras na internet, além do estudo com base nas referências bibliográficas relacionadas a habitação mínima e ergonomia.

A partir disso, foi elaborada um cálculo sobre a área útil média das plantas baixas catalogadas, gerando um diagnóstico com uma análise qualitativa sobre os parâmetros ergonômicos e de desempenho do imóvel com a área mais próxima da média encontrada. Posteriormente produzindo modificações na planta do apartamento, visando atender aos parâmetros de ergonomia e aos da NBR 15.575:2013.

A pesquisa identificou 96 apartamentos com área máxima de $70 \mathrm{~m}^{2}$, construídos nos últimos cinco anos por 17 construtoras, em 29 edifícios diferentes. A metodologia de trabalho consistiu no levantamento de informações em sites de construtoras. Os dados analisados e manipulados por 
meio da relação entre a quantidade de unidades e a tipologia de imóvel mais representativa.

Verificou-se que a tipologia de 2 quartos com suíte é a mais representativa, com $67,7 \%$ do total. Além disso, $100 \%$ das construtoras pesquisadas constroem este tipo de unidade habitacional. A preferência pelo mercado imobiliário pelo apartamento de 2 quartos com suíte é justificado pelo perfil da população do bairro Jardim Camburi, com características jovens e com menos número de pessoas por família.

Para a análise dos parâmetros de ergonomia, a pesquisa identificou as áreas úteis (somatória das áreas dos ambientes) das unidades pesquisadas, a partir do levantamento feito em plantas baixas dos pavimentos-tipos divulgados pelas construtoras para comercialização em seus sites.

O levantamento das tipologias de acordo com as suas áreas uteis, confirma o predomínio de unidades com área de 55 a $60 \mathrm{~m}^{2}$, com $27,1 \%$ de ocorrência, seguido por $25 \%$ de unidades com áreas úteis entre 50 e $55 \mathrm{~m}^{2}$, e $17,70 \%$ para unidades com área entre 45 e $50 \mathrm{~m}^{2}$ e 60 a $70 \mathrm{~m}^{2}$. Somente $1 \%$ das unidades

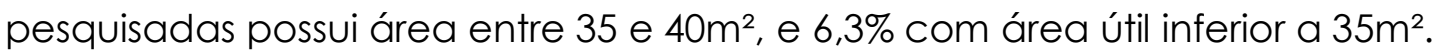

Para a elaboração das propostas de modificações nos apartamentos, foi escolhido o apartamento tipo com área útil de $52,84 \mathrm{~m}^{2}$ para análise ergonômica, verificando nos ambientes a sua funcionalidade por meio da inserção do espaço de atividades indicado por Boveri (2008) junto às dimensões dos mobiliários determinados pela norma ABNT NBR 15.575:2013 e pelo que é oferecido no mercado, através do levantamento de móveis por meio de pesquisas em meios digitais. Assim, foram elaboradas duas plantasbaixas modificadas com base na norma, no mobiliário padrão e nos aspectos de ergonomia.

\section{RESULTADOS E DISCUSSÕES}

A planta modificativa (figura 2) baseada na norma de desempenho (NBR 15.575), foi alterada de acordo com as medidas de mobiliário e equipamento que a norma determina, dessa forma foi necessário aumentar o quarto de solteiro, a sala de estar/jantar, a cozinha e área de serviço para que pudessem abrigar os elementos representados na habitação, sem modificar o modelo dos ambientes.

Destaca-se que a norma ABNT NBR 15.575:2013 apresenta sugestões de organização para os cômodos e dimensões de circulações compatíveis com as necessidades humanas. Recomenda-se que os projetos de arquitetura de edifícios habitacionais prevejam no mínimo a disponibilidade de espaço nos cômodos do edifício habitacional para colocação e utilização dos móveis e equipamentos-padrão.

Na figura 3, a planta modificativa baseada no mobiliário vendido pelo mercado de móveis divulgados na web, teve alteração na área útil da sala de estar/jantar, quarto de solteiro, na cozinha e área de serviço, para caber os mobiliários e a circulação.

Tendo como base o apartamento original com área útil de $52,84 \mathrm{~m}^{2}$, a pesquisa obteve duas plantas baixas modificadas, com área útil total de $59,22 \mathrm{~m}^{2}$ (modificada de acordo com os parâmetros exigidos pela norma de desempenho) e $61,07 \mathrm{~m}^{2}$ (planta baixa proposta de acordo com o mobiliário padrão disponibilizado no mercado). 
Percebe-se que as plantas modificativas sofreram um aumento significativo para que pudessem comportar os equipamentos e mobiliários juntos ao espaço de atividades e circulação, com uma variação de $6 \mathrm{~m}^{2}$ a $8 \mathrm{~m}^{2}$ por planta-baixa.

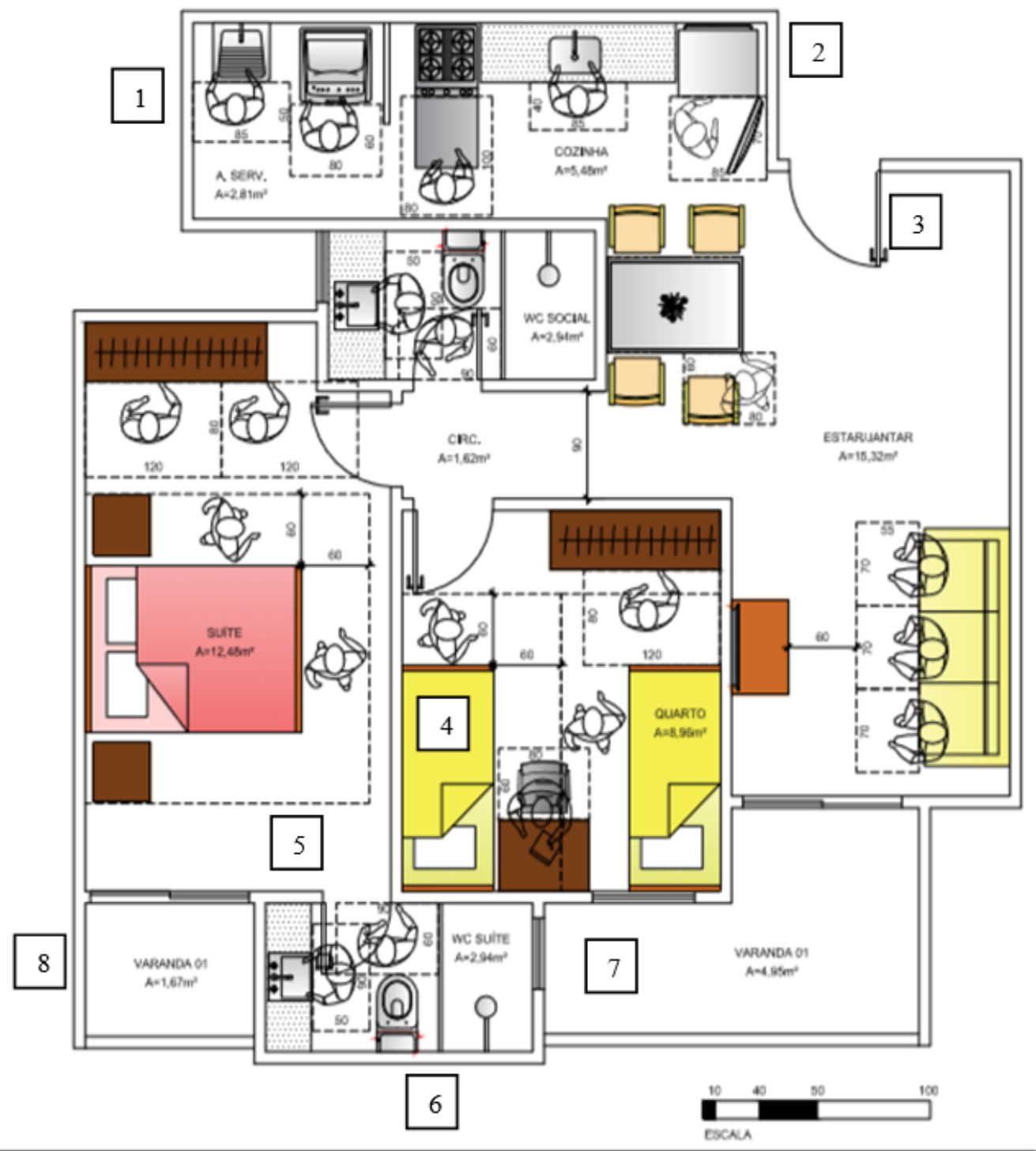

1) Na área de serviço foi necessário aumentar a largura e o comprimento do ambiente para que o espaço de atividades e os equipamentos pudessem ser inseridos sem que houvesse obstruções.

2) Também foi ampliada a cozinha a largura e o comprimento, porém õ fato da norma 15.575 não apresentar o freezer, possibilitou o uso de menos equipamentos fazendo com que seu tamanho sofresse uma modificação relativa.

3) Foi necessário aumentar a sala de jantar e estar para que a mobília e a área de atividades se acomodassem corretamente no ambiente, contando também com a circulação entre os móveis, sendo o mínimo $0,60 \mathrm{~m}$ de largura.

4) No quarto de solteiro para que duas camas pudessem ser inseridas como representado na planta-baixa original fornecida pela construtora junto com o espaço de atividades em frente ao armário, escrivaninha e circulação, foi preciso aumentar a largura e o comprimento, mas também há a possibilidade do uso de um beliche ou bicama, permitindo uma área menor.

5) Na suíte o mobiliário e a área de tarefa se encaixaram adequadamente, porém para que as paredes continuassem no mesmo eixo foi necessário que fossem movidas junto com as paredes compartilhadas dos ambientes modificados, aumentando a sua área.

6) Os banheiros não sofreram alterações, visto que seu espaço comporta tanto os equipamentos quanto os espaços de atividades.

7) O aumento que ocorreu na varanda da sala de estar sucedeu por conta das paredes que eram compartilhadas com os ambientes que foram alterados, permanecendo no mesmo

Figura 2 - Planta-baixa modificativa baseada na norma de desempenho (NBR 15.575Parte 1).

Fonte: Elaborada pelos autores, 2018 


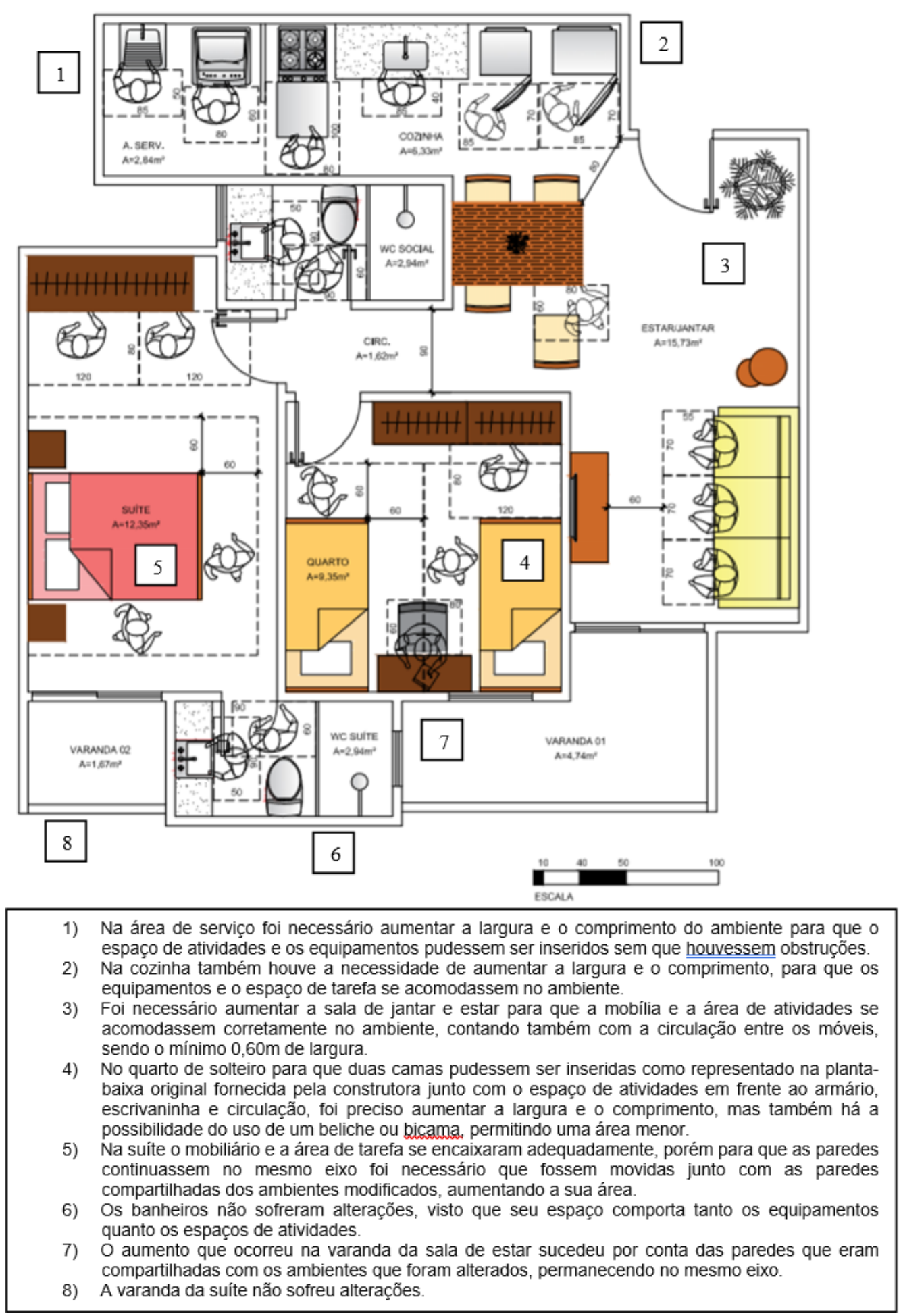

Figura 3 - Planta-baixa modificativa baseada no mobiliário fornecido pelo mercado Fonte: Elaborada pelos autores, 2018.

\section{CONSIDERAÇÕES FINAIS}

Ao propor a adequação de uma das plantas baixas dos apartamentos pesquisados aos padrões mínimos solicitados pela norma ABNT NBR 15.575:2013 e às dimensões de móveis comercializados no mercado, a pesquisa identificou que o imóvel deveria sofrer um acréscimo de área para se adaptar aos padrões de ergonomia e atender adequadamente aos usuários.

Essas modificações são resultados da má distribuição dos espaços nas habitações que vem sendo construídas de modo padronizado, sem se 
adequar aos novos perfis familiares, além de não acomodarem corretamente os mobiliários que são vendidos pelo mercado. Dessa maneira, visando uma melhor qualidade para as habitações verifica-se que há a necessidade de construções de habitações que propõem modelos flexíveis.

A prática pelo morar mínimo se apresenta cada vez mais nas construções da atualidade, devido aos perfis familiares, a especulação imobiliária e o novo modo de morar. Portanto, é importante que os profissionais da área da construção civil se conscientizem em relação a qualidade espacial e física dos ambientes dos apartamentos, para que possam produzir habitações de melhor qualidade e funcionamento, compatíveis com os requisitos de ergonomia e até mesmo, se possível, adequados a móveis disponíveis no mercado.

\section{REFERÊNCIAS}

ASSOCIAÇÃO BRASILEIRA DE NORMAS TÉCNICAS. NBR 15575-1: Edificações Habitacionais - Desempenho Parte 1: Requisitos gerais. 2013. Disponível em <http://360arquitetura.ara.br/wp-content/uploads/2016/01/NBR 1557512013 Final-Requisitos-Gerais.pdf> Acesso em: 25 mai. 2018.

BOUERI FILHO, José Jorge. Projeto e Dimensionamento dos Espaços da Habitação Espaço de Atividades. São Paulo: Estação das Letras e Cores, 2008. 48 p.; il.; $29,7 \mathrm{~cm}$. - Livro II.

CASELLI, Cristina Kanya. 100 anos de habitação mínima - Ênfase na Europa e Japão. 2007. 71 f. Dissertação de Mestrado em Arquitetura. Universidade Presbiteriana Mackenzie. São Paulo, 2007.

COSTA FILHO, Lourival Lopes. Discussão sobre a definição dimensional em apartamentos: Contribuição à ergonomia do ambiente construído. Dissertação de Mestrado em Design. 2005. 150 f.- Universidade Federal de Pernambuco. Recife, 2005.

CRECI-ES. Jardim Camburi, o bairro do presente e do futuro. Disponível em <http://www.crecies.gov.br/jardim-camburi-o-bairro-do-presente-e-do-futuro>. Consultado em: 01/08/2016.

GAZETAONLINE. Jardim Camburi é o campeão da valorização imobiliária. Disponível em:

<http://www.gazetaonline.com.br/_conteudo/2013/08/noticias/dinheiro/14560 75-jardim-camburi-e-o-campeao-de-valorizacao-imobiliaria.html>. Consultado em: 01/08/2016.

MENDONÇA, Rafaela Nunes; VILLA, Simone Barbosa. Apartamento mínimo contemporâneo - Desenvolvimento do conceito de uso como chave para obtenção de sua qualidade. V. 16 N. 4, Mai, 2016. Revista Ambiente Construído. Disponível em

<https://www.seer.ufrgs.br/ambienteconstruido/article/view/58792/38293>. Acesso em: 14 set. 2018.

MUNIZ, Andreia Fernandes; LOUREIRO, Priscilla Silva; KAPITZKY, Stephanie Heydy Avelino. MODOS MÍNIMOS DE MORAR: análise ergonômica sobre padrões dimensionais dos empreendimentos habitacionais multifamiliares: $O$ caso do bairro Jardim Camburi/Vitória-ES. Anais do I Congresso Arquitetura de Arquitetura e Cidade e IX Coletânea ArqUrb 2017. Disponível em < https://issuu.com/arqurbuvv/docs/congresso arq cidade>. Acesso em 09 jun. 2019. 
VAZ, Lílian Fessler. Modernidade e moradia - Habitação coletiva no Rio de Janeiro séculos XIX e XX. Rio de Janeiro: 7Letras, 2002. 